\title{
Phosphorylation of Ezrin/Radixin/Moesin Proteins by LRRK2 Promotes the Rearrangement of Actin Cytoskeleton in Neuronal Morphogenesis
}

\author{
Loukia Parisiadou, ${ }_{1}^{1}$ Chengsong Xie, ${ }^{1}$ Hyun Jin Cho, ${ }^{1}$ Xian Lin, ${ }^{1}$ Xing-Long Gu, ${ }^{1}$ Cai-Xia Long, ${ }^{1}$ Evy Lobbestael, ${ }^{2}$ \\ Veerle Baekelandt, ${ }^{2}$ Jean-Marc Taymans, ${ }^{2}$ Lixin Sun, ${ }^{1}$ and Huaibin Cai ${ }^{1}$ \\ ${ }^{1}$ Unit of Transgenesis, Laboratory of Neurogenetics, National Institute on Aging, National Institutes of Health, Bethesda, Maryland 20892, and ${ }^{2}$ Laboratory \\ for Neurobiology and Gene Therapy, Division of Molecular Medicine, Department of Molecular and Cellular Medicine, Faculty of Medicine, Katholieke \\ Universiteit Leuven, B-3000 Leuven, Belgium
}

Leucine-rich repeat kinase 2 (LRRK2) functions as a putative protein kinase of ezrin, radixin, and moesin (ERM) family proteins. A Parkinson's disease-related G2019S substitution in the kinase domain of LRRK2 further enhances the phosphorylation of ERM proteins. The phosphorylated ERM (pERM) proteins are restricted to the filopodia of growing neurites in which they tether filamentous actin (F-actin) to the cytoplasmic membrane and regulate the dynamics of filopodia protrusion. Here, we show that, in cultured neurons derived from LRRK2 G2019S transgenic mice, the number of pERM-positive and F-actin-enriched filopodia was significantly increased, and this correlates with the retardation of neurite outgrowth. Conversely, deletion of $L R R K 2$, which lowered the pERM and F-actin contents in filopodia, promoted neurite outgrowth. Furthermore, inhibition of ERM phosphorylation or actin polymerization rescued the G2019S-dependent neuronal growth defects. These data support a model in which the G2019S mutation of LRRK2 causes a gain-offunction effect that perturbs the homeostasis of pERM and F-actin in sprouting neurites critical for neuronal morphogenesis.

\section{Introduction}

Mutations in leucine-rich repeat protein kinase 2 (LRRK2) underlie the most common known genetic cause of familial and apparently sporadic Parkinson's disease (PD) cases (Paisán-Ruíz et al., 2004; Zimprich et al., 2004). The LRRK2 protein contains several distinctive structural and functional domains (see Fig. $1 A$ ). These include a Roc (Ras of complex proteins)/GTPase domain and a kinase domain that shares a high degree of homology with MAPKKK (mitogen-activated protein kinase kinase kinase) (Mata et al., 2006). The function of LRRK2 as a signaling molecule has therefore attracted a great deal of scrutiny. Interestingly, of all LRRK2 mutations that have been identified, the substitution of glycine at residue 2019 with serine (G2019S) at the activation segment of its kinase domain is the most commonly observed (Goldwurm et al., 2005; Bonifati, 2006). A number of studies in the absence of a physiological LRRK2 substrate indicate that the

\footnotetext{
Received Aug. 4, 2009; accepted Sept. 2, 2009.

This work was supported in part by National Institutes of Health (NIH)-National Institute on Aging Intramural Research Program Grant AG000944-01 and by Fonds Wetenschappelijk Onderzoek (FW0) Vlaanderen Grant G.0666.09, Institute for the Promotion of Innovation by Science and Technology in Flanders Grant IWT SB0/80020, and Katholieke Universiteit Leuven Grants IOF-KP/07/001 and 0T/08/052A. E.L. is a research assistant and J.-M.T. is a postdoctoral researcher of the Flemish Fund for Scientific Research (FWO Vlaanderen). We thank Dr. Zu-Hang Sheng for his helpful suggestions, Chris Van Den Haute and Anke Vander Perren for technical support, and the NIH Fellows Editorial Board for editing this manuscript.

The authors declare no competing financial interests.

Correspondence should be addressed to Huaibin Cai, Unit of Transgenesis, Laboratory of Neurogenetics, National Institute on Aging, National Institutes of Health, Building 35, Room 1A116, MSC 3707, 35 Convent Drive, Bethesda, MD 20892-3707. E-mail: caih@mail.nih.gov.

DOI:10.1523/JNEUROSCI.3799-09.2009

Copyright $\odot 2009$ Society for Neuroscience ～0270-6474/09/2913971-10\$15.00/0
}

G2019S substitution likely increases the kinase activity of LRRK2 (West et al., 2005; Greggio et al., 2006; Smith et al., 2006). Recently, Jaleel et al. (2007) reported that LRRK2 phosphorylates moesin at threonine 558 in vitro. However, whether moesin is a physiological substrate of LRRK2 remains to be determined.

Moesin together with ezrin and radixin are collectively known as ERM proteins. ERM proteins link the actin cytoskeleton with membrane proteins and play prominent roles in the determination of cell shape, growth, and motility (Mangeat et al., 1999; Bretscher et al., 2002). The activity of an ERM protein is regulated by the intramolecular interaction between the $\mathrm{N}$ - and C-terminal regions that leads to an "inactive" conformation and prevents the ERM protein from associating with other proteins, including filamentous actin (F-actin) (Turunen et al., 1994). The phosphorylation of a conserved threonine residue in the C-terminal domain of ERM proteins blocks the intramolecular association and induces a conformational change to an "active" state, which allows their association with F-actin and other proteins (Hirao et al., 1996).

Since MacLeod and colleagues have reported by both in vitro and in vivo experiments that LRRK2 is related to the maintenance of neuronal processes and neurite outgrowth (MacLeod et al., 2006), we speculated that LRRK2 may regulate neuronal development through modulation of ERM activities. To test this hypothesis, we examined the phosphorylation states of ERM proteins and the accumulation of F-actin in the filopodia of developing neurons derived from inducible transgenic mice overexpressing human LRRK2 wild type (WT) and G2019S, and LRRK2 knock-out $\left(L R R K 2^{-1-}\right.$ ) mice (Wang et al., 2008). We demonstrate here that ERM proteins are physiological substrates 
of the kinase activity of LRRK2. Furthermore, inhibition of excessive accumulation of phosphorylated ERM (pERM) and F-actin in the filopodia rescued the neurite growth defects in G2019S neurons, suggesting a gain-of-toxic function mechanism of this PD-related mutation in neuronal development and likely regeneration.

\section{Materials and Methods}

Generation of LRRK2 inducible transgenic mice. As described previously (Wang et al., 2008), cDNA fragments encoding full-length human WT and G2019S mutant LRRK2 were inserted into a tetracycline operatorregulated gene expression vector, pPrP-tetP (Jankowsky et al., 2005). The $\mathrm{C}$ termini of human LRRK2 protein were tagged with hemagglutinin (HA) epitope to facilitate protein identification. The $\mathrm{F}_{1}$ transgenic mice were crossed with CaMKII-tTA mice (Mayford et al., 1996) to achieve high expression of LRRK 2 in the forebrain region. The mice were housed in a $12 \mathrm{~h}$ light/dark cycle and fed regular diet ad libitum. All mouse work followed the guidelines approved by the Institutional Animal Care and Use Committees of the National Institute of Child Health and Human Development.

Generation of LRRK2 knock-out mice. A genomic DNA fragment carrying the first two coding exons of LRRK2 was isolated from the RPCI-22 (129S6/SvEvTac) Mouse BAC Library (BACPAC Resources Center). One copy of a LoxP site was inserted into intron 1 followed by an insertion of a FRT-flanked neomycin expression cassette and the second copy of LoxP site into intron 2 of $L R R K 2$. The targeting vector was linearized and transfected into $129 / \mathrm{SvJ}$ embryonic stem (ES) cells, which were later subjected to G418 selection for $7 \mathrm{~d}$. The G418 resistant ES clones were picked and screened by Southern blot analysis for the correctly targeted clones. Two positive ES clones were expanded and injected into blastocysts. The resulting male chimera mice were bred with wild-type C57BL/6J female mice to obtain $L R R K 2^{+/ \text {neo }}$ mice. $L R R K 2^{+/ \text {neo }}$ mice were then crossed with Cre transgenic mice (Lakso et al., 1996) to generate $L R R K 2^{+/-}$mice in which exon 2 was deleted by Cre-mediated DNA recombination, resulting in a premature stop codon in exon 3 . The heterozygous $L R R K 2^{+/-}$mice were intercrossed to generate the homozygous LRRK2 $2^{-1-}$ mice.

Generation of LRRK2 antibody. An anti-LRRK2 serum (DR4EC9E) was produced via immunization of rabbits with a keyhole limpet hemocyanin-coupled peptide. The peptide sequence corresponds to a rodent sequence in the C-terminal region of LRRK2 (from residues 2495 to 2515: SIWDLNLPHEVQNLEKHIEVRT).

Primary neuronal cell culture. Primary neurons from hippocampus, cortex, and striatum were prepared from newborn (postnatal day 0) pups, as described previously (Cai et al., 2005). Briefly, neurons were dissociated by papain (Sigma-Aldrich) buffer. They were placed in polyD-lysine (BD Biosciences) plates in Basal Eagle Medium (Sigma-Aldrich) supplemented with B27, N2, $1 \mu \mathrm{M}$ L-glutamine, and penicillin/streptomycin (Invitrogen). Arabinosylcytosine (Sigma-Aldrich) was used to inhibit glial cell growth. The medium was changed every $2 \mathrm{~d}$. Forskolin A (1 $\mu \mathrm{M})$ (Millipore Bioscience Research Reagents), latrunculin A (LTA) $(1 \mu \mathrm{M})$ (Calbiochem), doxycycline (Dox) (1 $\mu \mathrm{M})$ (Sigma-Aldrich), (9S,10S,12R)2,3,9,10,11,12-hexahydro-10-hydroxy-9-methyl-1-oxo-9,12-epoxy- $1 \mathrm{H}$ diindolo[1,2,3-fg:3',2', 1'-kl]pyrrolo[3,4-i] [1,6] benzodiazocine-10-carboxylic acid hexyl ester (KT5720) $(1 \mu \mathrm{M})$ (Sigma-Aldrich), N-[2-(( $p$ bromocinnamyl)amino)ethyl]-5-isoquinolinesulfonamide, $2 \mathrm{HCl}$ (H89) $(10 \mu \mathrm{M})$ (Calbiochem), 2-[N-(2-hydroxyethyl)]-N-(4-methoxybenzenesulfonyl)amino- $\mathrm{N}$-(4-chlorocinnamyl- $\mathrm{N}$-methyl-benzylamine) (KN-93) (10 $\mu \mathrm{M})($ Calbiochem), deltamethrin $(10 \mu \mathrm{M})$ (Calbiochem), and Rho kinase inhibitor II (RKI II) $(100 \mu \mathrm{M})$ (Calbiochem) were added directly to the medium from stock solutions.

Transfection of primary neurons. Primary hippocampal neurons at $10 \mathrm{~d}$ in culture were transfected with a membrane-targeted green fluorescent protein (GFP) expression vector (Benediktsson et al., 2005) using the calcium phosphate method as described by Jiang and Chen (2006). Briefly, neuronal cultures were incubated with the DNA-calcium phosphate precipitate for $\sim 1.5 \mathrm{~h}$. After incubation, the precipitate was dissolved by incubation for $15 \mathrm{~min}$ in a medium that had been preequilibrated in a $10 \%$
$\mathrm{CO}_{2}$ incubator. The plates were in turn returned to their original conditioned medium and checked the next day for GFP expression. Cells were fixed $48 \mathrm{~h}$ after transfection.

Immunofluorescence staining. For immunofluorescent staining not involving ERM proteins, neurons were fixed at $2 \mathrm{~d}$ in vitro (DIV) in $37^{\circ} \mathrm{C}$, $4 \%$ paraformadehyde (PFA). The cultures were permeabilized with $0.1 \%$ Triton X-100 in PBS, incubated with $10 \%$ goat serum (Sigma-Aldrich) for $1 \mathrm{~h}$ at $37^{\circ} \mathrm{C}$ to block nonspecific staining, and then incubated with primary antibodies overnight. For staining involving pERM and total ERM, the neurons were fixed in 4\% PFA with 10\% trichloroacetic acid. Primary antibodies used included pERM and total ERM (1:200; Cell Signaling) and $\beta$ III-tubulin (1:3000; Sigma-Aldrich). The F-actin staining was performed using Alexa Fluor 568 phalloidin according to the manufacturer's protocol (Invitrogen).

Image acquisition and quantification. Fluorescent images were captured using a Zeiss confocal microscope (LSM 510 META). The length of neurites, the area of positive F-actin staining at $2 \mathrm{DIV}$, as well as total neurite length of 12 DIV GFP-expressed neurons, were determined using the appropriate tools of the NIH ImageJ software. More specifically, by using the line tools and setting the scale to micrometer unit, we measured the length of neurites. In the length quantification, we only included cells that have already extended neurites. Cells with no processes were excluded from the analysis. We performed the area determination by choosing "area" in the setting measurements, and in this case, we set the appropriate unit, square micrometer. For measuring the intensity of fluorescence signal, the build-in Zeiss LSM510 Meta imaging software was used. Under the histogram section, a number of drawing tools were used to define the areas of interest (i.e., growth cones), and the mean fluorescence intensity was measured by the software. In each experiment, the histograms represent the length or the area of 50-120 neurons (unless otherwise stated) sampled from three randomly selected microscopic fields of at least three independent experiments from a person blind to the genotype of the neurons.

Western blot. Total brains and primary cortical neurons were lysed at $4^{\circ} \mathrm{C}$ in lysis buffer [50 mм Tris- $\mathrm{HCl}, 150 \mathrm{~mm} \mathrm{NaCl}, 2$ mм EDTA, pH 7.6, $2 \%$ SDS (v/v)] supplemented with complete protease inhibitor mixture (Roche Applied Biosciences) and phosphatase inhibitor mixture (Pierce Biotechnology). Homogenates were centrifuged at $2500 \times g$ to remove nuclei and no soluble tissues, and the supernatants were separated by $4-12 \%$ NuPage Bis-Tris PAGE (Invitrogen) and transferred to nitrocellulose membranes. Membranes were incubated with the appropriate dilutions of the primary antibodies overnight at $4^{\circ} \mathrm{C}$. Antibodies specific for LRRK2 (1:1000), pERM, total ERM (1:1000; Cell Signaling) that are directed against a highly conserved sequence shared between all ERM proteins and $\beta$-tubulin (1:3000; Sigma-Aldrich) were used. Protein bands were detected by using the enhanced chemiluminescence (ECL) system (Pierce Biotechnology) and quantified using the Scion Image System.

ERM peptide synthesis. The ERM peptide was synthesized as described previously (Tamma et al., 2005) with slight modifications. More specifically, a short sequence in the C-terminal end of the ERM family of proteins including the conserved threonine residue was connected by a disulfuric bond to the cysteine of a hydrophobic 20 aa chain that constitutes a permeable helix for the introduction of the peptide into the cells. The addition of the fluorochrome dansyl to the hydrophobic chain allowed its visualization inside the cells, confirming its internalization. A control peptide with a reversed sequence was additionally synthesized. The final concentration of the peptide applied to the cells was $1 \mu \mathrm{M}$.

Statistical analysis. Statistical analysis was performed using GraphPad Prism 5 (GraphPad Software) and StatView program (SAS Institute). Statistical significances were determined by comparing means of different groups using $t$ test or ANOVA followed by post hoc Tukey's honestly significant difference test. Error bars indicate SEM. ${ }^{*} p<0.05 ;{ }^{* *} p<0.01$; ${ }^{* * *} p<0.001$.

\section{Results}

LRRK2 regulates the morphogenesis of developing neurons

LRRK2 is implicated in the maintenance of neuronal processes (MacLeod et al., 2006). To examine whether LRRK2 is involved 

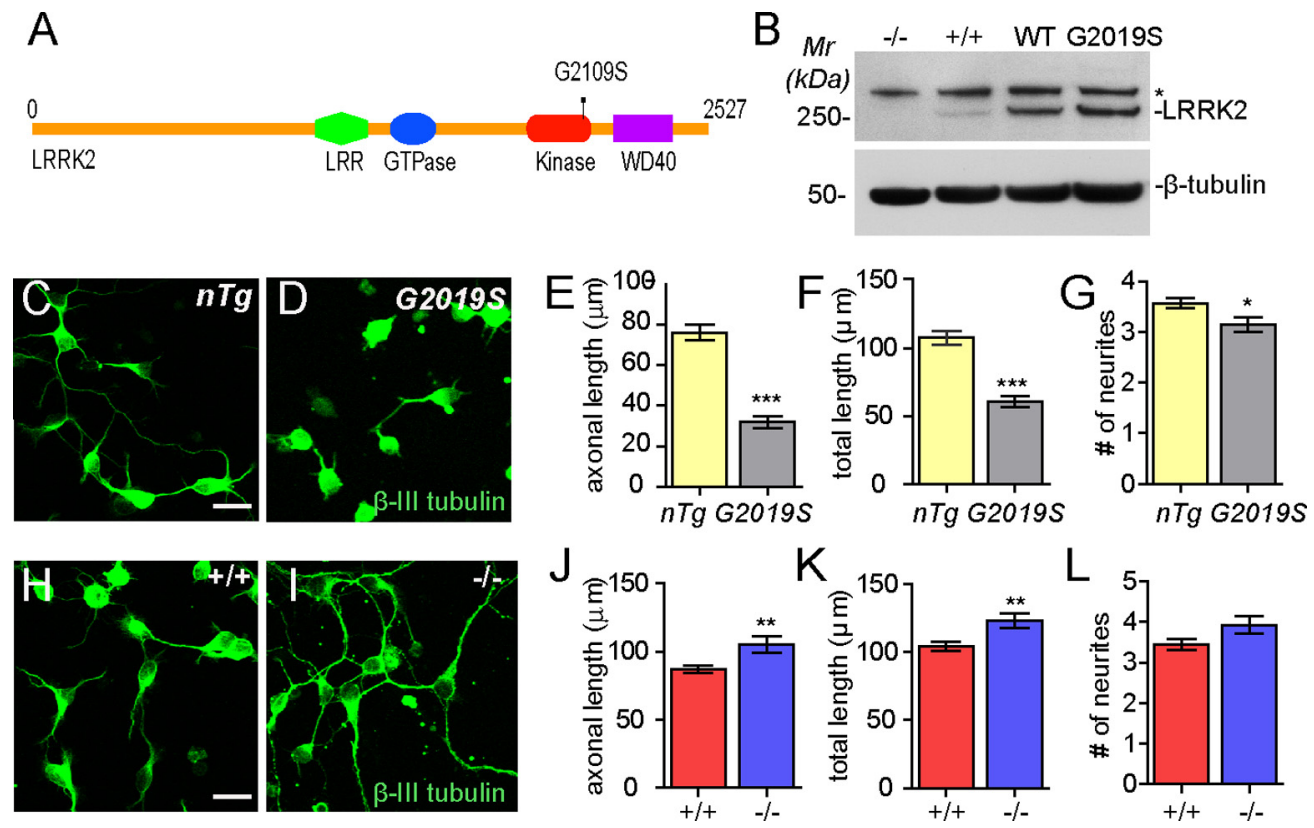

Figure 1. LRRK2 regulates the morphogenesis of developing neurons at 2 DIV. A, A schematic sketch shows the structural and functional domains of LRRK2 protein. LRR, Leucine-rich repeat. $\boldsymbol{B}$, Western blot reveals the expression of exogenous LRRK2 in WT and G2019S LRRK2 transgenic mouse brain homogenates using an antibody against the C-terminal tail of LRRK2. C, $\boldsymbol{D}$, Representative images show cultured hippocampal neurons (2 DIV) from littermate $n T g(\boldsymbol{C})$ and $G 20195$ (D) pups. Neurites were visualized by staining with $\beta$ III-tubulin antibody. Scale bar, $100 \mu \mathrm{m}$. E-G, Bar graphs depict quantitative analyses of axonal length $(\boldsymbol{E})$, total neurite length $(\boldsymbol{F})$, and the number of primary neurites $(\boldsymbol{G})$ from the neurons described in $\boldsymbol{C}$ and $\boldsymbol{D}$. Fifty to 150 neurons were analyzed from each genotype. Data represent mean \pm SEM. ${ }^{*} p<0.05 ;{ }^{* *} p<0.01 ;{ }^{* * *} p<0.001$. H, I, Representative images show cultured hippocampal neurons (2 DIV) from littermate LRRK2 ${ }^{+/+}(+/+$;

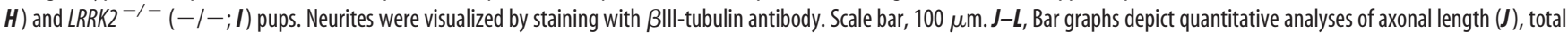
neurite length $(\boldsymbol{K})$, and the number of primary neurites $(\boldsymbol{L})$ from the neurons described in $\boldsymbol{H}$ and $\boldsymbol{I}$. Fifty to 150 neurons were analyzed from each genotype. Data represent mean $\pm S E M$. ${ }^{* *} p<0.01$.
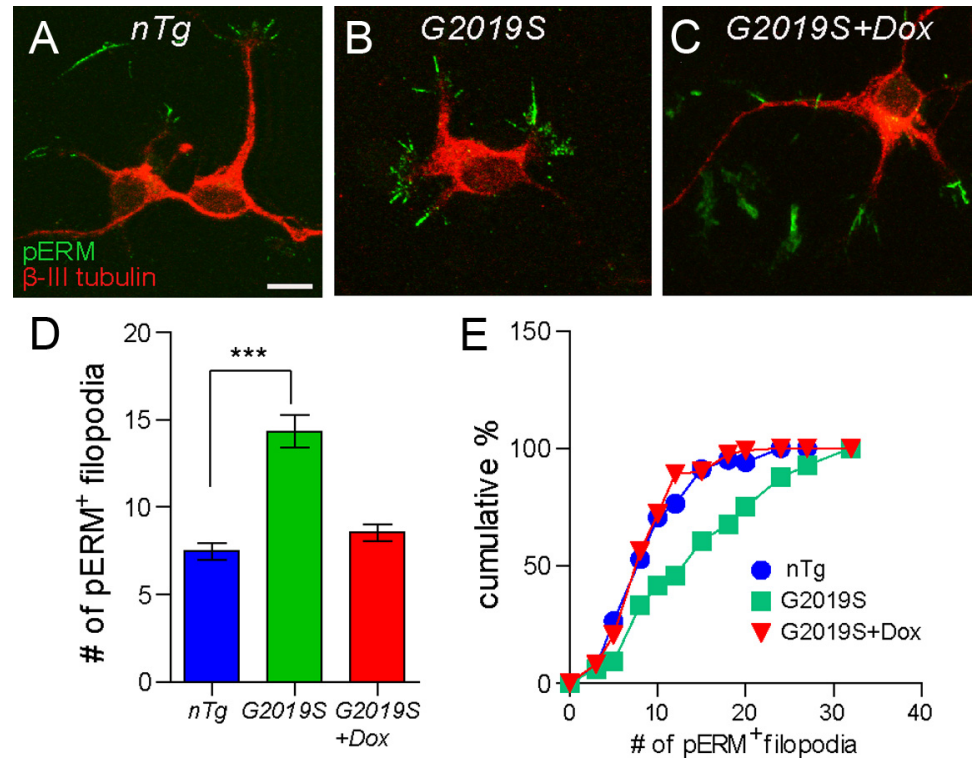

Figure 2. Overexpression of LRRK2 G2019S mutation increases the phosphorylation of ERM proteins in the filopodia of developing neurons. $\boldsymbol{A}-\boldsymbol{C}$, Representative images show pERM (green) staining in primary cultured hippocampal neurons (2 DIV) from littermate $n T g(\boldsymbol{A})$ and $\mathrm{G} 20195(\boldsymbol{B})$ pups. A fraction of $\mathrm{G} 20195$ neurons was treated with Dox $(\boldsymbol{C})$. Neurons were counterstained with $\beta$ III-tubulin antibody (red). Scale bar, $20 \mu \mathrm{m}$. D, Bar graph depicts the number of pERM-positive $\left(\mathrm{pERM}^{+}\right)$filopodia in the distal tips of neurites per neuron $(N=100-120$ per genotype). Data represent mean $\pm S E M$. ${ }^{* * *} p<0.001$. $E$, Cumulative frequency plot for the numbers of pERM ${ }^{+}$filopodia in $n T g$ (blue), G2019S (green), and G2019S+Dox (red) neurons.

in neuronal morphogenesis, we cultured hippocampal neurons isolated from newborn pups overexpressing either WT or G2019S LRRK2, and with the deletion of LRRK2 $\left(\right.$ LRRK2 $\left.^{-1-}\right)$ (Fig. $1 B$ ). The expression level of exogenous human LRRK2 protein in both WT and G2019S LRRK2 transgenic mice is $\sim 8$ - to
16 -fold above the level of endogenous mouse protein (X. L. Gu, unpublished data). We compared the length and number of primary neurites after 2 DIV with neurons derived from their littermate controls. Compared with neurons from the control nontransgenic ( $n \mathrm{Tg}$ ) littermates (Fig. 1C), neurons derived from G2019S pups displayed shortened neurites (Fig. $1 D$ ), including both the longest process that corresponds to the axon (Fig. $1 E)(p<0.001)$ as well as total neurite length (Fig. $1 F)(p<0.001)$. G2019S neurons also displayed a reduced number of primary neurites (Fig. 1G) $(p=$ $0.0151)$. In contrast, $L R R K 2^{-1-}$ neurons showed a significant increase in the length of neurites (Fig. 1I) compared with their littermate control $L R R K 2^{+/+}$neurons (Fig. $1 H$ ) with respect to the longest process (Fig. $1 J)(p=0.0056)$ as well as an increase in total neurite outgrowth (Fig. $1 K)(p=0.0023)$. The number of primary neurites, however, was not significantly altered in $L R R K 2^{-1-}$ neurons (Fig. $1 L$ ). Since the expression of G2019S is under the control of the tetracyclineregulated system (Wang et al., 2008), we also treated the G2019S neurons with Dox immediately after plating to suppress the expression of G2019S. Dox treatment rescued the inhibitory effect of G2019S on neurite outgrowth (Wang et al., 2008). To determine whether the effect of the G2019S mutation on neurite outgrowth is the result of a 

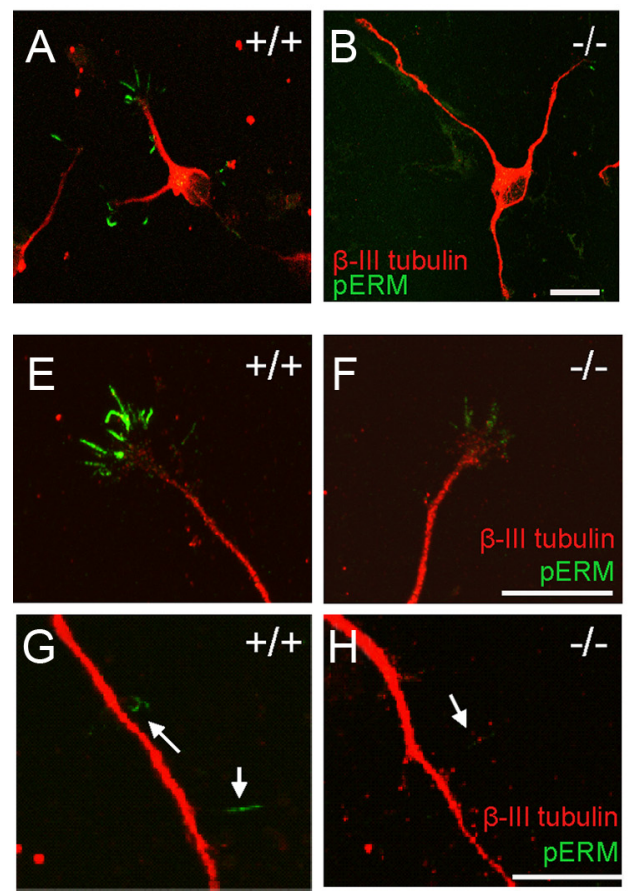
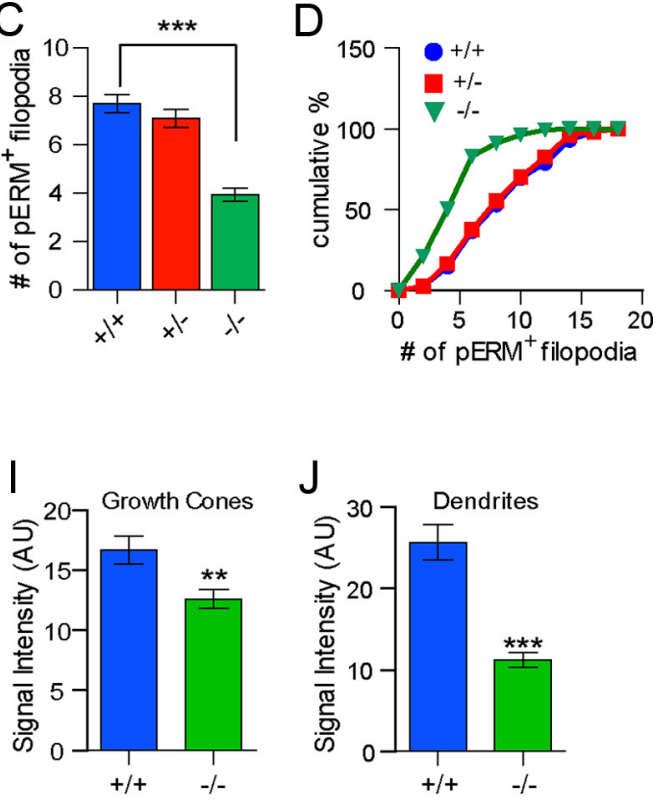

Figure 3. Phosphorylation of ERM proteins is significantly reduced in the distal tips of primary $L R R K 2^{-/-}$neurons. $\boldsymbol{A}, \boldsymbol{B}$, Representative images show $L R R K 2^{+/+}(\boldsymbol{A})$ and $\angle R R K 2^{-/-}(\boldsymbol{B})$ hippocampal neurons (2 DIV) immunostained with $\beta$ III-tubulin (red) and pERM (green) antibodies. Neuron cultures were derived from littermate pups. Scale bar, $20 \mu \mathrm{m}$. $\boldsymbol{C}$, Bar graph depicts the number of $E_{E R M}{ }^{+}$filopodia per neuron in $L R R K 2^{+/+}, L R R K 2^{+/-}$, and $L R R K 2^{-1-}$ neurons $\left(n=85-120\right.$ per genotype). Data represent mean \pm SEM. ${ }^{* * *} p<0.001 . D$, Cumulative frequency plot for the number of pERM-positive filopodia per neuron in $L R R K 2^{+/+}, L R R K 2^{+/-}$, and $L R R K 2^{-/-}$neurons. $\boldsymbol{E}-\boldsymbol{H}$, Sample images of $L R R K 2^{+/+}(\boldsymbol{E}, \boldsymbol{G})$ and $L R R K 2^{-\prime-}(\boldsymbol{F}, \boldsymbol{H})$ hippocampal neurons show $\beta$ III-tubulin (red) and pERM (green) staining at growth cone $(\boldsymbol{E}, \boldsymbol{F})$ and dendritic $(\boldsymbol{G}, \boldsymbol{H})$ filopodia, respectively. $\boldsymbol{I}, \boldsymbol{J}$, Bar graphs depict the intensity of pERM-positive immunofluorescent signal at both the growth cone and dendritic filopodia of $L R R K 2^{+/+}$and $L R R K 2^{-/-}$neurons $\left(n=80-100\right.$ per genotype). Data represent mean \pm SEM. ${ }^{* *} p<0.01{ }^{* * *} p<0.001$.

putative gain-of-function mechanism and not simply caused by overexpression of $L R R K 2$, we also quantified the outgrowth of neurites from neurons of WT LRRK2 inducible transgenic mice. These mice displayed similar level of LRRK2 expression as mice with the G2019S mutation (Fig. $1 B$ ). It appeared that overexpression of WT LRRK2 had no significant effect on the development of neuronal processes (supplemental Fig. S1B-E, available at www.jneurosci.org as supplemental material) compared with littermate controls (supplemental Fig S1A, available at www. jneurosci.org as supplemental material). Collectively, these observations demonstrate that LRRK2 is physiologically involved in the early development of neuronal processes and the putative gain of function of G2019S mutation compromised the outgrowth of neurites.

After establishing a functional involvement of LRRK2 in the developing neurons, we decided to explore the effect of G2019S on more mature hippocampal neurons. To visualize individual neurons and follow the extension of their neurites, we transfected $n T g$ and G2019S neurons at 10 DIV with plasmids encoding a membrane-bound GFP and fixed the neurons $2 \mathrm{~d}$ after transfection (supplemental Fig. S2 A, $B$, available at www.jneurosci.org as supplemental material). We found a similar reduction in the neurite length at this time point (supplemental Fig. S2C, available at www.jneurosci.org as supplemental material) $(p<0.01)$, further demonstrating the effect of G2019S mutation in neuronal morphogenesis.

\section{LRRK2 modulates the phosphorylation of ERM proteins}

Jaleel et al. (2007) identified ERM proteins as potential substrates of LRRK2 in vitro. LRRK2 phosphorylates a conserved threonine residue in these proteins, which results in their activation (Bretscher et al., 2002). The pERM proteins have been localized to the actin-rich sites in filopodia and play a key role in neurite outgrowth by regulating filopodia restructuring (Paglini et al., 1998). Based on these previous studies, we decided to investigate whether ERM proteins are indeed physiological substrates of LRRK2 and also whether the modulation of ERM phosphorylation is the means by which LRRK2 exerts its effect on neurite outgrowth. To address this hypothesis, we examined the levels of pERM proteins in cultured hippocampal neurons derived from G2019S (Fig. 2B), G2019S treated with Dox (Fig. 2C), and LRRK2 $2^{-I-}$ pups (Fig. 3), as well as WT LRRK2 transgenic animals (supplemental Fig. S3, available at www.jneurosci.org as supplemental material), and compared them with neurons derived from their littermate controls. Similar to previous observations (Ramesh, 2004; Haas et al., 2007), pERM was primarily located at the filopodia in neurons (Fig. $2 A-C$ ). We calculated the average numbers of pERM-positive filopodia per neuron in $n T g$ (Fig. 2A), G2019S (Fig. 2B), and G2019S treated with Dox (G2019S+Dox) cultures (Fig. 2C). We found a significant increase in the per-neuron number of pERM-positive filopodia in G2019S neurons compared with littermate controls (Fig. 2D) $(p<0.001)$. Moreover, the percentage of neurons with more pERM-positive filopodia was also significantly increased in G2019S neurons (Fig. 2E). The application of Dox suppressed this phenomenon (Fig. 2C-E). We then examined the presence of pERM-positive filopodia in cultured hippocampal neurons derived from littermate control nTg (supplemental Fig. S3A, available at www.jneurosci.org as supplemental material) and WT LRRK2 (supplemental Fig. S3B, available at www.jneurosci.org as supplemental material) pups. The average number of pERMpositive filopodia in each neuron (supplemental Fig. S3C, available at www.jneurosci.org as supplemental material) as well as the distribution of pERM-positive filopodia (supplemental Fig. 

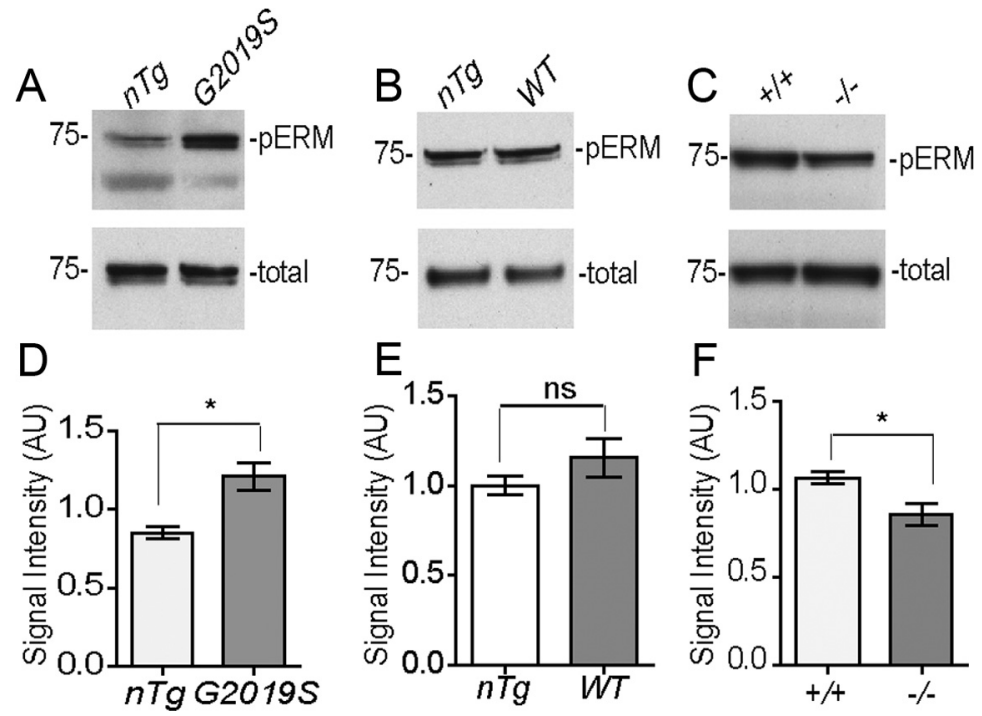

Figure 4. Western blot analyses of pERM level in cortical neurons derived from $n T g, G 20195$, WT $L R R K 2, \angle R R K 2^{+/+}$and LRRK2 $^{-{ }^{-}}$pups. $\boldsymbol{A}-\boldsymbol{C}$, Cortical neurons at 2 DIV derived from littermate $n T g$ and $G 2019 S(\boldsymbol{A}), n T g$ and WT LRRK2 (B), and littermate $L R R K 2^{+/+}$and $L R R K 2^{-1-}(\boldsymbol{C})$ pups were analyzed by Western blot using a pERM antibody. $\boldsymbol{D}-\boldsymbol{F}$, Bar graphs depict the quantification of pERM levels normalized by total ERM in respective samples ( $n \geq 3$ per genotype). Data represent mean \pm SEM. ${ }^{*} p<0.05$.
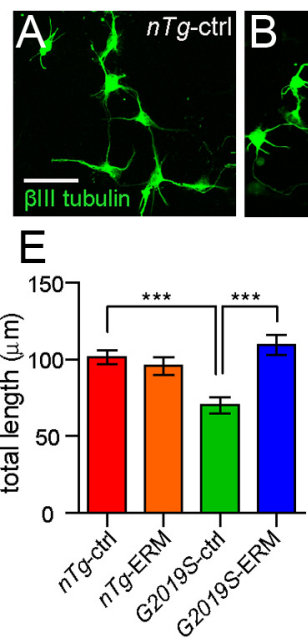

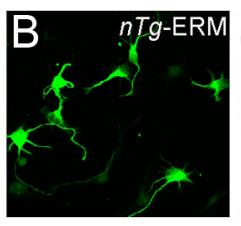

$\mathrm{F}$

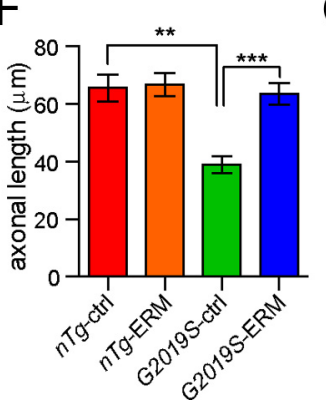

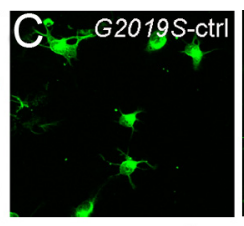

G

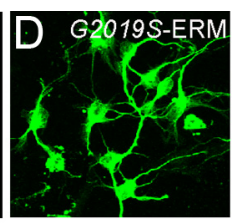

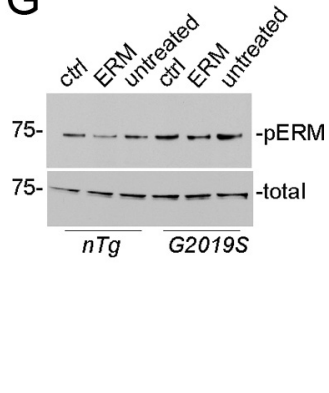

Figure 5. Suppression of ERM phosphorylation rescues the inhibitory effect of $G 20195$ on neuron morphogenesis. $\boldsymbol{A}-\boldsymbol{D}$, Representative images show $n T g(\boldsymbol{D}, \boldsymbol{F})$ and $G 20195(\boldsymbol{E}, \boldsymbol{G})$ primary hippocampal neurons (2 DIV) derived from littermate pups stained by $\beta$ III-tubulin after treated with either a control (ctrl) $(\boldsymbol{A}, \boldsymbol{C})$ or ERM peptides (ERM) $(\boldsymbol{B}, \boldsymbol{D})$. Scale bar, $100 \mu \mathrm{m}$. $\boldsymbol{E}, \boldsymbol{F}$, Bar graphs depict the axonal length $(\boldsymbol{E})$ and total neurite length $(\boldsymbol{F})$ of neurons treated with either control or ERM peptides $(n=50-100$ per genotype and condition). Data represent mean \pm SEM. ${ }^{* *} p<0.01 ;{ }^{* * *} p<0.001$. G, Primary cultured cortical neurons were treated with control (ctrl) or ERM peptides, and the levels of pERM and total ERM were examined by Western blot.

S3C, available at www.jneurosci.org as supplemental material) were comparable between WT LRRK2 and littermate control $n T g$ neurons. These results are consistent with our early observations that neurons overexpressing WT LRRK2 grew normally during development (supplemental Fig. S1, available at www.jneurosci. org as supplemental material).

To further investigate whether ERM proteins are physiological substrates of LRRK2, we checked the levels of pERM in cultured $L R R K 2^{-1-}$ hippocampal neurons and littermate controls. Fewer pERM-positive filopodia were found in $L R R K 2^{-1-}$ neurons (Fig. $3 B$ ) compared with littermate $L R R K 2^{+/+}$neurons at 2 DIV (Fig. 3A). Both the average number of pERM-positive filopodia in each neuron (Fig. 3C) and the percentage of neurons with more pERM-positive filopodia (Fig. 3D) were significantly de- creased in $L R R K 2^{-1-}$ neurons relative to $L R R K 2^{+/+}$and $L R R K 2^{+/-}$neurons $(p<$ $0.0001)$. The reduction of pERM staining in $L R R K 2^{-I-}$ neurons happened at both the axonal growth cone (Fig. $3 F, I)(p<$ 0.005 ) and dendritic filopodia (Fig. $3 \mathrm{H}, \mathrm{J}$ ) $(p<0.0001)$ compared with littermate control LRRK2 $2^{+/+}$neurons (Fig. $3 E, G$ ).

In addition to immunostaining of neurons, we also examined the level of pERM in cortical neurons at 2 DIV by Western blot (Fig. 4). A significant increase in pERM levels $(p=0.0195)$ was found in G2019S (Fig. 4A, $C$ ) cortical neurons, but no difference was observed in WT LRRK2 neurons (Fig. $4 B, D$ ) compared with littermate $n T g$ controls. On the contrary, a significant decrease of pERM in $L R R K 2^{-1-}$ primary neurons $(p=0.0470)$ was found compared with $L R R K 2^{+/+}$controls (Fig. $4 C, E)$. However, no significant change was detected in pERM levels in the total brain lysates of different genotypes (supplemental Fig. S5, available at www. jneurosci.org as supplemental material), likely resulting from the overwhelming contribution of pERM from astrocytes.

\section{Inhibition of ERM phosphorylation rescues the neurite outgrowth defects in G2019S neurons}

Our early observations indicate that the increased accumulation of pERM in the filopodia of G2019S neurons may contribute to the reduced extension of neurites. Therefore, to test whether the aberrant phosphorylation of ERM is directly involved, we decided to evaluate the effect of inhibiting ERM phosphorylation on neurite outgrowth in G2019S neurons. Similar to a previous study (Tamma et al., 2005), we synthesized an ERM peptide corresponding to the highly conserved C-terminal sequence containing the phosphorylation site, and a control polypeptides consisting of same residues in the reverse order. With the attachment of a stretch of hydrophobic sequence and a photoactivated tag, these polypeptides are able to penetrate the plasmic membrane and be visualized by its fluorescence localization (supplemental Fig. S6A-D, available at www.jneurosci.org as supplemental material). The exogenous application of this peptide would compete with the endogenous ERM proteins for phosphorylation (Fig. 5G). In turn, we showed the presence of the ERM peptides associated with neurons $3 \mathrm{~h}$ (supplemental Fig. S6A, C, available at www.jneurosci.org as supplemental material) after its application and also just before fixation at $\sim 48 \mathrm{~h}$ after plating (supplemental Fig. $\mathrm{S} 6 B, D$, available at www.jneurosci.org as supplemental material). G2019S (Fig. 5C,D) and littermate control $n T g$ (Fig. $5 A, B)$ neurons were treated with the ERM or control peptides at a final concentration of $1 \mu \mathrm{m}$ throughout the total culture period. The neurons were fixed after $2 \mathrm{~d}$ in culture for the measurement of neurites. Application of ERM peptides led to a reversal of the inhibitory 
effect of G2019S on neurite outgrowth as indicated by the analysis of both axonal and total neurite length compared with neurons treated with the control peptide (Fig. $5 E, F$ ). As expected, the introduction of ERM peptides led to a reduction of pERM by Western blots (Fig. 5G).

\section{LRRK2 is involved in actin remodeling}

ERM proteins act as linkers of cytoplasmic membrane proteins to the actin cytoskeleton (Turunen et al., 1994; Bretscher et al., 2002). On phosphorylation, the intramolecular association of ERM proteins is disrupted and their C-terminal domains bind to F-actin (Ramesh, 2004). In addition, the early stages of neuron development are characterized by a sequence of events in which the dynamic remodeling of actin plays a prominent role (Bradke and Dotti, 1999). Therefore, there seems to exist a close relationship between ERM phosphorylation, actin remodeling, and neurite outgrowth. To examine the role of LRRK2 on actin dynamics, we determined the F-actin levels in the growth cones of cultured $n T g, L R R K 2$ G2019S transgenic (Fig. 6A,B), LRRK2 $2^{+/+}$, and LRRK2 $2^{-1-}$ hippocampal neurons (Fig. $6 D, E$ ) at 2 DIV.F-actin was revealed by staining with phalloidin (Capani et al., 2001). A significant increase in the size of F-actin-positive area was found in the filopodia of G2019S neurons compared with littermate $n T g$ neurons (Fig. 6C) $(p<0.0001)$. In contrast, neurons from $L R R K 2^{-l-}$ mice showed a significant reduction in the size of F-actin-positive area in their filopodia compared with controls (Fig. $6 F)(p=0.0210)$. Additionally, no significant alteration of F-actin staining was found at the growth cones of WT LRRK2 transgenic neurons (L. Parisiadou and C. Xie, unpublished data).

To further elucidate the role of the G2019S mutation in F-actin accumulation, we treated cells with a heat shock protein 90 specific inhibitor (PU-H71) that reduces the steady level of LRRK2 protein (Wang et al., 2008). As expected, a reduction of F-actin staining was observed in PU-H71-treated G2019S neurons (Fig. $6 H$ ) compared with vehicle-treated neurons (Fig. 6G). Moreover, the application of Dox also reversed the effect of G2019S on the abnormal accumulation of F-actin at filopodia (Fig. 6I). Together, these data clearly demonstrate that the LRRK2 G2019S mutation is involved in accumulating F-actin in filopodia during neuronal development.

\section{Reduction of F-actin content rescues the outgrowth defect of G2019S neurons}

To directly address a connection between the increased actin polymerization to neurite morphogenesis, we applied the F-actin depolymerizing agent LTA or vehicle (DMSO) to cultured hippocampal neurons derived from G2019S and littermate control $n T g$ mice (Fig. $7 A-L$ ). We performed pilot experiments to determine the optimum dose and presence time of the drug to avoid toxicity and exert its effect. Thus, we used the following strategy. Twelve hours after plating, neurons were treated with either $1 \mu \mathrm{M}$ LTA or vehicle for $36 \mathrm{~h}$ and then fixed for histological analysis.
The specific concentration and application time of the drug seemed to have a profound actin-depolymerizing effect for both $n T g$ (Fig. 7D) and G2019S (Fig. 7J) neurons. Interestingly, incubation of G2019S neurons with the drug was associated with a significant increase of neurite length, compared with control DMSO-treated cells (Fig. $7 M)(p<0.005)$. It did not, however, significantly change the length of $n \mathrm{Tg}$ neurons at the concentration of LTA used in this study. These results strongly indicated that increased F-actin content at the filopodia of G2019S neurons may account for the neurite outgrowth defect. Noticeably, the application of ERM peptides and treatment with Dox also suppressed the enhanced actin polymerization in G2019S neurons (Fig. $7 \mathrm{~N}, \mathrm{O}$ ).

\section{Forskolin blocks the inhibitory effect of G2019S on the outgrowth of neurites}

To further elucidate the intracellular signal transduction pathways by which G2019S regulates neuronal morphogenesis, we treated the neurons with a number of inhibitors and activators related with second messenger pathways. Among them, the application of forskolin (FSK), an activator of adenylyl cyclase, resulted in a LRRK2-related effect. FSK $(1 \mu \mathrm{M})$ or vehicle was applied to G2019S and littermate $n T g$ neurons throughout the culture period (Fig. $8 A-D$ ). At $2 \mathrm{DIV}$, the axonal length and total neurite length were determined. Interestingly, FSK reversed the neurite outgrowth and branching defects in G2019S neurons (Fig. $8 E-G)(p<0.001$ and $p<0.002$, respectively). Under the same conditions, a slight but not significant increase of neurite outgrowth was found in littermate control $n T g$ neurons. Since a 

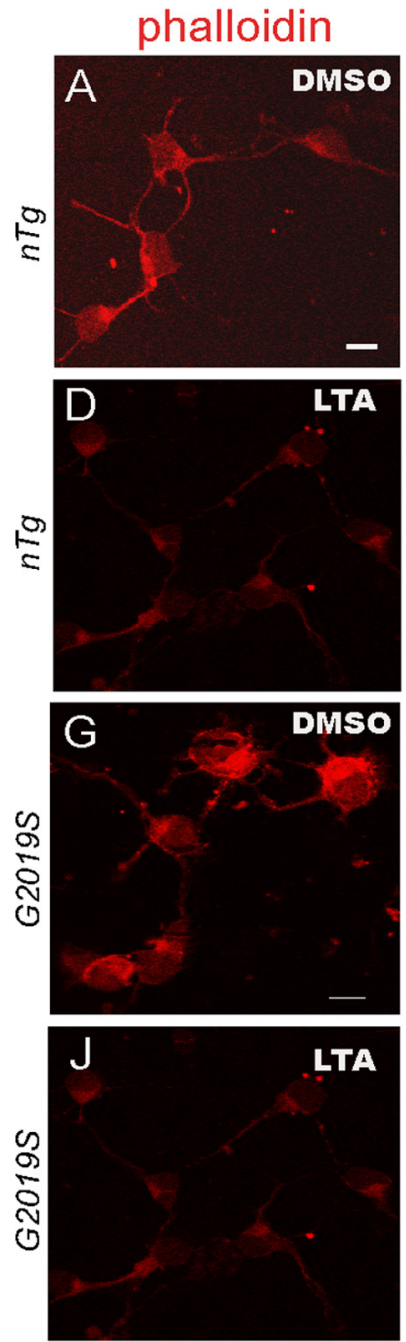

M

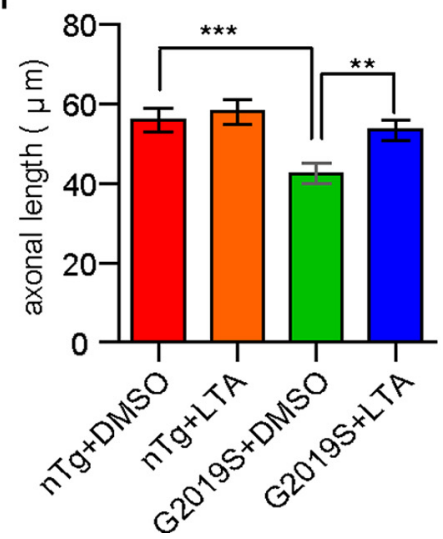

Blll-tubulin

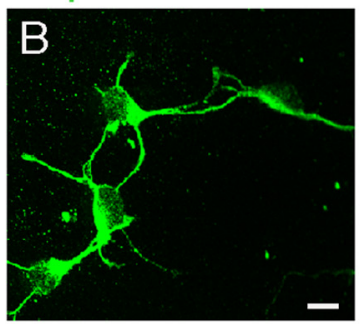

merged
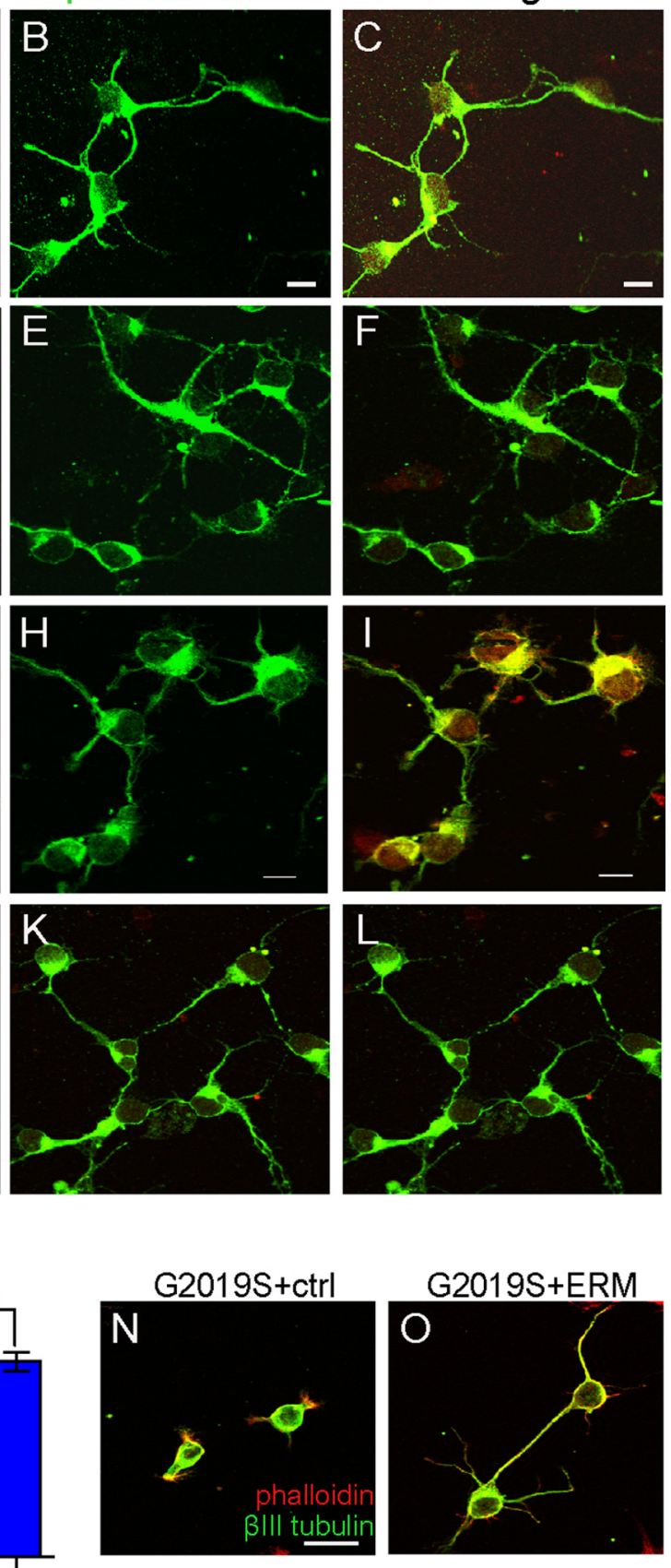

G2019S+ERM

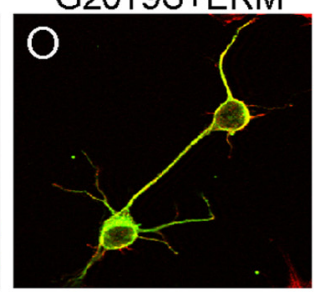

Figure 7. Disruption of F-actin accumulation rescues the G2019S-related effect on neurite outgrowth. $\boldsymbol{A}-\boldsymbol{L}$, Representative images show $n T g(\boldsymbol{A}-\boldsymbol{F})$ and $62019 S$ (G-L) hippocampal neurons (at 2 DIV) stained with phalloidin (red) and $\beta$ III-tubulin (green) after being treated with LTA (1 $\mu \mathrm{m}$ ) or the vehicle (DMSO). Scale bar, $20 \mu \mathrm{m}$. $\boldsymbol{M}$, Bar graph depicts the axon length of $n T g$ and G2019S neurons treated with either vehicle control or LTA. Data represent mean \pm SEM. ${ }^{* *} p<0.01 ;{ }^{* * *} p<0.001 . \mathbf{N}, \mathbf{0}$, Representative images display G2019S hippocampal neurons (at 2 DIV) stained with phalloidin (red) and $\beta$ III-tubulin (green) after being treated with control (ctrl) or ERM peptides (ERM). Scale bar, $20 \mu \mathrm{m}$.

previous study indicates that FSK leads to a decrease of ERM phosphorylation (Tamma et al., 2005), we speculated that this could also be the case for G2019S neurons. Indeed, the number of ERM-positive filopodia in FSK-treated G2019S developing neurons was significantly reduced compared with vehicle-retreated controls (Fig. $8 H-J)(p<0.02)$. In addition, the level of pERM in the FSK-treated neuronal homogenate was significantly decreased compared with vehicle-treated controls (Fig. $8 \mathrm{~K}$ ). FSK incubation has been also reported to result in partial depolymerization of the actin cytoskeleton (Klussmann and Rosenthal, 2001; Tamma et al., 2003). Consistent with these early studies, we showed that the aberrant accumulation of F-actin was diminished in FSKtreated G2019S neurons compared with the vehicle-treated controls (Fig. $8 L, M$ ).

A number of additional chemicals, such as deltamethrin (calcineurin inhibitor), KN-93 (CaMKII inhibitor), RKII (Rho kinase inhibitor), and KT5720 and H89 (protein kinase A inhibitor), however, showed a genotype-independent effect on neurite outgrowth (Parisiadou and Xie, unpublished data). For example, the application of RKII in LRRK2 $2^{-/-}$and littermate control $L R R K 2^{+/+}$neurons showed a similar degree of reduced neurite length in accordance with a previous observation (Haas et al., 2007), indicating that this is a more general effect based on the inhibition of the Rho kinase activity, rather than a rescue effect (Parisiadou and Xie, unpublished data). The chemical used and their relative effect are summarized in Table 1.

\section{Discussion}

Since the identification of PD-associated mutations in $L R R K 2$, many studies have attempted to characterize the physiological function of LRRK2, especially its kinase activity (Giasson and Van Deerlin, 2008). Here, we establish that LRRK2 is essential to neurite outgrowth through its regulation of the phosphorylation of ERM proteins and actin polymerization. We found that, compared with their control littermates, overexpression of LRRK2 G2019S mutation inhibited neurite outgrowth, enhanced the phosphorylation of ERM proteins, and increased the content of F-actin in filopodia, whereas deletion of $L R R K 2$ promoted the extension of neurites, suppressed the phosphorylation of ERM proteins, and decreased the content of F-actin in filopodia. More importantly, the suppression of ERM protein phosphorylation or inhibition of actin polymerization rescued the developmental defects of G2019S neurons, suggesting that ERM proteins and F-actin are genuine downstream targets of LRRK2 during neuronal morphogenesis. In addition, overexpression of WT $L R R K 2$ had no significant effect on the neuronal morphogenesis, which further establishes the gain-of-function mechanism of the G2019S mutation in LRRK2. 

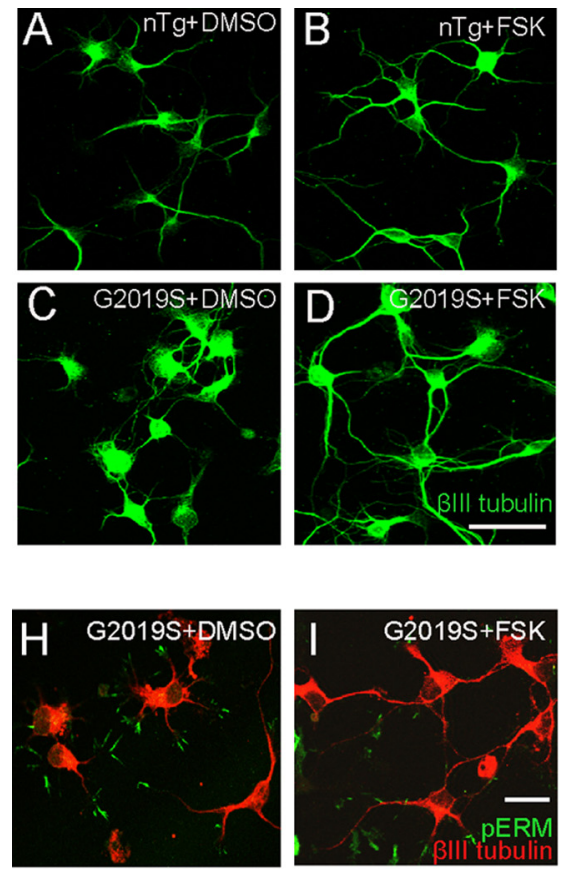
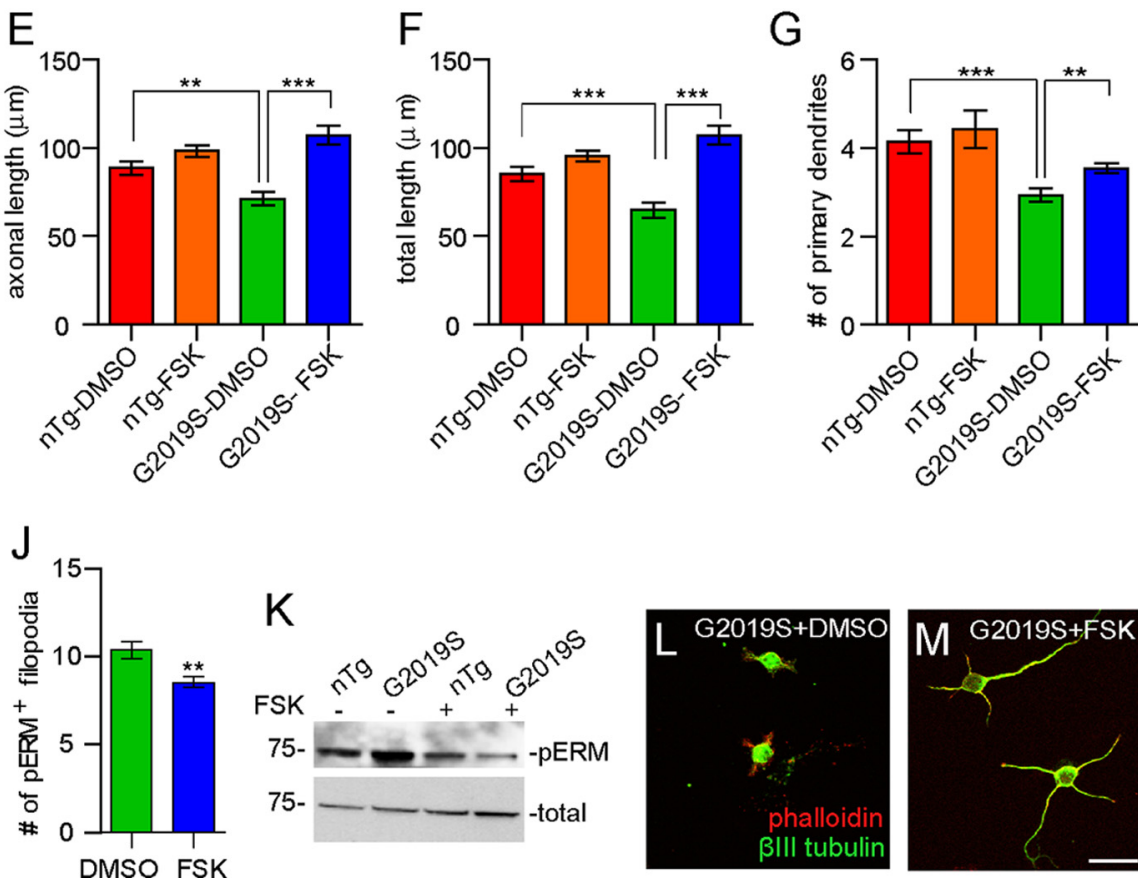
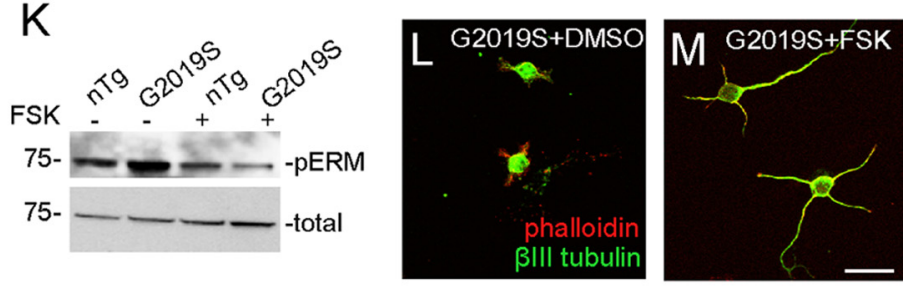

Figure 8. Forskolin application reverses the G2019S-dependent neuronal growth defects. $\boldsymbol{A}-\boldsymbol{D}$, Representative images show $n T g(\boldsymbol{A}, \boldsymbol{B})$ and $G 20195(\boldsymbol{C}, \boldsymbol{D})$ hippocampal neurons stained with $\beta$ III-tubulin after treatment with DMSO $(\boldsymbol{A}, \boldsymbol{C})$ or FSK $(\boldsymbol{B}, \boldsymbol{D})$. $\boldsymbol{E}-\boldsymbol{G}$, Bar graphs represent the quantification of axonal length $(\boldsymbol{E})$, total neurite length $(\boldsymbol{F})$, and the number of primary neurites $(\boldsymbol{G})$ of vehicle- or FSK-treated $n T g$ and $G 2019$ S neurons. $\boldsymbol{H}, \boldsymbol{I}$, Representative images display G2019S neurons stained with $\beta$ III-tubulin (red) and pERM (green) after treatment with either DMSO ( $\boldsymbol{H}$ ) or FSK (I). $\boldsymbol{J}$, Bar graph depicts the number of pERM-positive filopodia presented in $\boldsymbol{H}$ and $\boldsymbol{I}$ ( $n=53$ per genotype). Data represent mean \pm SEM. ${ }^{* *} p<0.01$, ${ }^{* * *} p<0.001$. $\boldsymbol{K}$, Western blot analyses of pERM in lysates from $n T g$ and G2019S cortical neurons after treatment with DMSO ( - ) or FSK (+). L, M, Representative images show G2019S neurons (at 2 DIV) stained with phalloidin (red) and $\beta$ III-tubulin (green) after treatment with DMSO (L) or FSK (M). Scale bar, $20 \mu \mathrm{m}$.

Table 1. A list of pharmacological agents tested in primary neurons and their relative effects on neurite outgrowth

\begin{tabular}{|c|c|c|}
\hline Pharmacological agents & $\begin{array}{l}\text { Genotype where } \\
\text { applied }\end{array}$ & Relative effects \\
\hline $\begin{array}{l}\text { Deltamethrin, } 10 \mu \mathrm{M} \\
\quad \text { (calcineurin inhibitor) }\end{array}$ & $n T g$ and 620195 & $\begin{array}{l}\text { No significant effect in either } \\
\text { genotype }\end{array}$ \\
\hline $\begin{array}{l}\text { KN-93, } 10 \mu \mathrm{m} \text { (CaMKII } \\
\text { inhibitor) }\end{array}$ & $n T g$ and 620195 & $\begin{array}{l}\text { Increased the number and shortened } \\
\text { the length of neurites in } n T g \\
\text { neurons }\end{array}$ \\
\hline $\begin{array}{l}\text { KT5720, } 1 \mu \mathrm{M} \text { (PKA } \\
\text { inhibitor) }\end{array}$ & $n T g$ and 620195 & No significant effect in either genotype \\
\hline $\begin{array}{l}\text { Forskolin, } 1 \mu \mathrm{m} \text { (adenylyl } \\
\text { cyclase activator) }\end{array}$ & $n T g$ and 620195 & $\begin{array}{l}\text { Significantly rescued the growth } \\
\text { defects of G2019S neurons }\end{array}$ \\
\hline $\begin{array}{l}\text { RKI II, } 100 \mu \mathrm{m} \text { (Rho kinase } \\
\text { inhibitor) }\end{array}$ & $\begin{array}{l}\angle R R K 2^{+1+} \text { and } \\
\qquad \text { LRRK2 }^{-1-}\end{array}$ & $\begin{array}{l}\text { Reduced the neurite length in both } \\
\text { genotypes }\end{array}$ \\
\hline $\begin{array}{l}\mathrm{H} 89,10 \mu \mathrm{M} \text { (PKA } \\
\text { inhibitor) }\end{array}$ & $\begin{array}{l}\angle R R K 2^{+1+} \text { and } \\
\qquad \text { LRRK2 }^{-1-}\end{array}$ & $\begin{array}{l}\text { Reduced the neurite length in both } \\
\text { genotypes }\end{array}$ \\
\hline
\end{tabular}

PKA, Protein kinase A.

In support of previous observations from cell-free studies (Jaleel et al., 2007; Anand et al., 2009), we found that the level of pERM proteins was significantly elevated in developing G2019S neurons as demonstrated by the increased number of pERM-positive axonal and dendritic filopodia. The effect of ERM phosphorylation on neuronal morphogenesis was assessed by modulating the pERM levels in the filopodia of G2019S neurons. We synthesized ERM peptides similar to one previously described that contains the conserved phosphorylation site of ERM proteins (Tamma et al., 2005). Incubation with ERM peptides decreased the phosphorylation of ERM proteins and rescued the growth defects of G2019S neurons. Moreover, the level of pERM was significantly decreased in the filopodia of
$L R R K 2^{-1-}$ neurons compared with $L R R K 2^{+/+}$controls, establishing a physiological link between LRRK2 and pERM in the development of neurons. Together, these results strongly suggest that ERM proteins are physiological substrates of LRRK2 kinase activity and the increased presence of pERM in the filopodia contributes to the developmental defects of G2019S neurons.

pERM links F-actin to the plasma membrane, with their $\mathrm{N}$ termini binding directly or indirectly to membrane proteins and their C termini binding directly to F-actin (Tsukita et al., 1994). Proper neurite outgrowth and subsequent axon formation depend on a dynamic balance of F-actin at the peripheral area and microtubules at the central domain of the filopodia (Baas et al., 1989; Bridgman and Dailey, 1989). Although the exact mechanism remains undetermined, one widely accepted hypothesis suggests that the instability of F-actin favors the protrusion and formation of axons (Bradke and Dotti, 2000). At the very early stages of neuron development, the filopodial dynamics are similar among all of the neurites in which F-actin restricts additional protrusion of microtubules (Bradke and Dotti, 2000). Later, F-actin becomes less stable in one of the neurites, allowing the protrusion of microtubules and formation of axons (Bradke and Dotti, 1999). Consistent with previous observations (Castelo and Jay, 1999), we found that the F-actin content in the filopodia corresponded with the level of pERM. More specifically, G2019S neurons displayed a significant increase of positive F-actin staining in the filopodia compared with control neurons. Therefore, in the presence of the G2019S mutation, the abnormally increased F-actin in the filopodia may act as a "barrier" to block the extension of microtubules and inhibit the outgrowth of neurites (Bradke and Dotti, 1999). In line with this notion, the application of an F-actin depolymerizing agent led to the reversal of the neurite outgrowth defect in G2019S neurons. 
Previous protein binding assays establish the physical interaction between LRRK2 and ERM proteins. However, at subcellular level, where and when LRRK2 modifies the phosphorylation state of ERM proteins remains elusive. LRRK2 is primarily located in the soma and proximal neurites (supplemental Fig. S4A, available at www.jneurosci.org as supplemental material) (Biskup et al., 2006), whereas pERM is predominantly enriched in the filopodia (Fig. 2; supplemental Fig. $\$ 4 B$, available at www.jneurosci. org as supplemental material). We speculate that LRRK2 may phosphorylate ERM proteins in the cytosol (supplemental Fig. S4C, available at www.jneurosci.org as supplemental material) and the resulting pERM may then be recruited to the filopodia through interaction with cytoplasmic membrane proteins. Additionally, we also investigated other intracellular signaling pathways (summarized in Table 1), which are potentially involved in the neuronal morphogenesis. We found that it was the application of forskolin that reversed the G2019S-dependent growth defect. It has been previously reported that the activation of protein kinase A (induced by forskolin application) leads to depolymerization of F-actin through phosphorylation of RhoA (Lang et al., 1996; Ellerbroek et al., 2003; Tamma et al., 2003). This mechanism may also apply to the forskolin-induced reversal of neurite growth in G2019S neurons.

In summary, our study establishes a critical connection between LRRK2 and F-actin remodeling through its modulation of ERM activities. We demonstrate that the increased activation of ERM proteins and the resulting abnormal accumulation of F-actin in filopodia account for the neurite outgrowth defects in G2019S neurons. It remains to determine how this abnormal function of LRRK2 G2019S mutation contributes to the degeneration of midbrain dopaminergic neurons in PD. Haas et al. (2007) reported a role for pERM in neurite regeneration. Therefore, one potential model would be an involvement of LRRK2 in promoting the sprouting of surviving neurites to compensate for the loss of neurons during the progression of PD. Our results indicate that the G2019S mutation may hinder the regeneration of neurites in the PD brain as it did during development, resulting in potentially accelerated neuronal degeneration in $\mathrm{PD}$.

\section{References}

Anand VS, Reichling LJ, Lipinski K, Stochaj W, Duan W, Kelleher K, Pungaliya P, Brown EL, Reinhart PH, Somberg R, Hirst WD, Riddle SM, Braithwaite SP (2009) Investigation of leucine-rich repeat kinase 2: enzymological properties and novel assays. FEBS J 276:466-478.

Baas PW, Black MM, Banker GA (1989) Changes in microtubule polarity orientation during the development of hippocampal neurons in culture. J Cell Biol 109:3085-3094.

Benediktsson AM, Schachtele SJ, Green SH, Dailey ME (2005) Ballistic labeling and dynamic imaging of astrocytes in organotypic hippocampal slice cultures. J Neurosci Methods 141:41-53.

Biskup S, Moore DJ, Celsi F, Higashi S, West AB, Andrabi SA, Kurkinen K, Yu SW, Savitt JM, Waldvogel HJ, Faull RL, Emson PC, Torp R, Ottersen OP, Dawson TM, Dawson VL (2006) Localization of LRRK2 to membranous and vesicular structures in mammalian brain. Ann Neurol 60:557-569.

Bonifati V (2006) Parkinson's disease: the LRRK2-G2019S mutation: opening a novel era in Parkinson's disease genetics. Eur J Hum Genet 14:1061-1062.

Bradke F, Dotti CG (1999) The role of local actin instability in axon formation. Science 283:1931-1934.

Bradke F, Dotti CG (2000) Changes in membrane trafficking and actin dynamics during axon formation in cultured hippocampal neurons. Microsc Res Tech 48:3-11.

Bretscher A, Edwards K, Fehon RG (2002) ERM proteins and merlin: integrators at the cell cortex. Nat Rev Mol Cell Biol 3:586-599.

Bridgman PC, Dailey ME (1989) The organization of myosin and actin in rapid frozen nerve growth cones. J Cell Biol 108:95-109.
Cai H, Lin X, Xie C, Laird FM, Lai C, Wen H, Chiang HC, Shim H, Farah MH, Hoke A, Price DL, Wong PC (2005) Loss of ALS2 function is insufficient to trigger motor neuron degeneration in knock-out mice but predisposes neurons to oxidative stress. J Neurosci 25:7567-7574.

Capani F, Ellisman MH, Martone ME (2001) Filamentous actin is concentrated in specific subpopulations of neuronal and glial structures in rat central nervous system. Brain Res 923:1-11.

Castelo L, Jay DG (1999) Radixin is involved in lamellipodial stability during nerve growth cone motility. Mol Biol Cell 10:1511-1520.

Ellerbroek SM, Wennerberg K, Burridge K (2003) Serine phosphorylation negatively regulates RhoA in vivo. J Biol Chem 278:19023-19031.

Giasson BI, Van Deerlin VM (2008) Mutations in LRRK2 as a cause of Parkinson's disease. Neurosignals 16:99-105.

Goldwurm S, Di Fonzo A, Simons EJ, Rohé CF, Zini M, Canesi M, Tesei S, Zecchinelli A, Antonini A, Mariani C, Meucci N, Sacilotto G, Sironi F, Salani G, Ferreira J, Chien HF, Fabrizio E, Vanacore N, Dalla Libera A, Stocchi F, et al. (2005) The G6055A (G2019S) mutation in LRRK2 is frequent in both early and late onset Parkinson's disease and originates from a common ancestor. J Med Genet 42:e65.

Greggio E, Jain S, Kingsbury A, Bandopadhyay R, Lewis P, Kaganovich A, van der Brug MP, Beilina A, Blackinton J, Thomas KJ, Ahmad R, Miller DW, Kesavapany S, Singleton A, Lees A, Harvey RJ, Harvey K, Cookson MR (2006) Kinase activity is required for the toxic effects of mutant LRRK2/ dardarin. Neurobiol Dis 23:329-341.

Haas MA, Vickers JC, Dickson TC (2007) Rho kinase activates ezrinradixin-moesin (ERM) proteins and mediates their function in cortical neuron growth, morphology and motility in vitro. J Neurosci Res 85:34-46.

Hirao M, Sato N, Kondo T, Yonemura S, Monden M, Sasaki T, Takai Y, Tsukita S, Tsukita S (1996) Regulation mechanism of ERM (ezrin/ radixin/moesin) protein/plasma membrane association: possible involvement of phosphatidylinositol turnover and Rho-dependent signaling pathway. J Cell Biol 135:37-51.

Jaleel M, Nichols RJ, Deak M, Campbell DG, Gillardon F, Knebel A, Alessi DR (2007) LRRK2 phosphorylates moesin at threonine-558: characterization of how Parkinson's disease mutants affect kinase activity. Biochem J 405:307-317.

Jankowsky JL, Slunt HH, Gonzales V, Savonenko AV, Wen JC, Jenkins NA, Copeland NG, Younkin LH, Lester HA, Younkin SG, Borchelt DR (2005) Persistent amyloidosis following suppression of Abeta production in a transgenic model of Alzheimer disease. PLoS Med 2:e355.

Jiang M, Chen G (2006) High $\mathrm{Ca}^{2+}$-phosphate transfection efficiency in low-density neuronal cultures. Nat Protoc 1:695-700.

Klussmann E, Rosenthal W (2001) Role and identification of protein kinase A anchoring proteins in vasopressin-mediated aquaporin-2 translocation. Kidney Int 60:446-449.

Lakso M, Pichel JG, Gorman JR, Sauer B, Okamoto Y, Lee E, Alt FW, Westphal H (1996) Efficient in vivo manipulation of mouse genomic sequences at the zygote stage. Proc Natl Acad Sci U S A 93:5860-5865.

Lang P, Gesbert F, Delespine-Carmagnat M, Stancou R, Pouchelet M, Bertoglio J (1996) Protein kinase A phosphorylation of RhoA mediates the morphological and functional effects of cyclic AMP in cytotoxic lymphocytes. EMBO J 15:510-519.

MacLeod D, Dowman J, Hammond R, Leete T, Inoue K, Abeliovich A (2006) The familial Parkinsonism gene LRRK2 regulates neurite process morphology. Neuron 52:587-593.

Mangeat P, Roy C, Martin M (1999) ERM proteins in cell adhesion and membrane dynamics. Trends Cell Biol 9:187-192.

Mata IF, Wedemeyer WJ, Farrer MJ, Taylor JP, Gallo KA (2006) LRRK2 in Parkinson's disease: protein domains and functional insights. Trends Neurosci 29:286-293.

Mayford M, Bach ME, Huang YY, Wang L, Hawkins RD, Kandel ER (1996) Control of memory formation through regulated expression of a CaMKII transgene. Science 274:1678-1683.

Paglini G, Kunda P, Quiroga S, Kosik K, Cáceres A (1998) Suppression of radixin and moesin alters growth cone morphology, motility, and process formation in primary cultured neurons. J Cell Biol 143:443-455.

Paisán-Ruíz C, Jain S, Evans EW, Gilks WP, Simón J, van der Brug M, López de Munain A, Aparicio S, Gil AM, Khan N, Johnson J, Martinez JR, Nicholl D, Carrera IM, Pena AS, de Silva R, Lees A, Martí-Massó JF, Pérez-Tur J, Wood NW, et al. (2004) Cloning of the gene containing 
mutations that cause PARK8-linked Parkinson's disease. Neuron 44: $595-600$.

Ramesh V (2004) Merlin and the ERM proteins in Schwann cells, neurons and growth cones. Nat Rev Neurosci 5:462-470.

Smith WW, Pei Z, Jiang H, Dawson VL, Dawson TM, Ross CA (2006) Kinase activity of mutant LRRK2 mediates neuronal toxicity. Nat Neurosci 9:1231-1233.

Tamma G, Klussmann E, Procino G, Svelto M, Rosenthal W, Valenti G (2003) cAMP-induced AQP2 translocation is associated with RhoA inhibition through RhoA phosphorylation and interaction with RhoGDI. J Cell Sci 116:1519-1525.

Tamma G, Klussmann E, Oehlke J, Krause E, Rosenthal W, Svelto M, Valenti G (2005) Actin remodeling requires ERM function to facilitate AQP2 apical targeting. J Cell Sci 118:3623-3630.

Tsukita S, Oishi K, Sato N, Sagara J, Kawai A, Tsukita S (1994) ERM family members as molecular linkers between the cell surface glycoprotein CD44 and actin-based cytoskeletons. J Cell Biol 126:391-401.
Turunen O, Wahlström T, Vaheri A (1994) Ezrin has a COOH-terminal actin-binding site that is conserved in the ezrin protein family. J Cell Biol 126:1445-1453.

Wang L, Xie C, Greggio E, Parisiadou L, Shim H, Sun L, Chandran J, Lin X, Lai C, Yang WJ, Moore DJ, Dawson TM, Dawson VL, Chiosis G, Cookson MR, Cai H (2008) The chaperone activity of heat shock protein 90 is critical for maintaining the stability of leucine-rich repeat kinase 2 . J Neurosci 28:3384-3391.

West AB, Moore DJ, Biskup S, Bugayenko A, Smith WW, Ross CA, Dawson VL, Dawson TM (2005) Parkinson's disease-associated mutations in leucine-rich repeat kinase 2 augment kinase activity. Proc Natl Acad Sci U S A 102:16842-16847.

Zimprich A, Biskup S, Leitner P, Lichtner P, Farrer M, Lincoln S, Kachergus J, Hulihan M, Uitti RJ, Calne DB, Stoessl AJ, Pfeiffer RF, Patenge N, Carbajal IC, Vieregge P, Asmus F, Müller-Myhsok B, Dickson DW, Meitinger T, Strom TM, et al. (2004) Mutations in LRRK2 cause autosomal-dominant parkinsonism with pleomorphic pathology. Neuron 44:601-607. 